\title{
Multiple voices: Learners reflect on literature
}

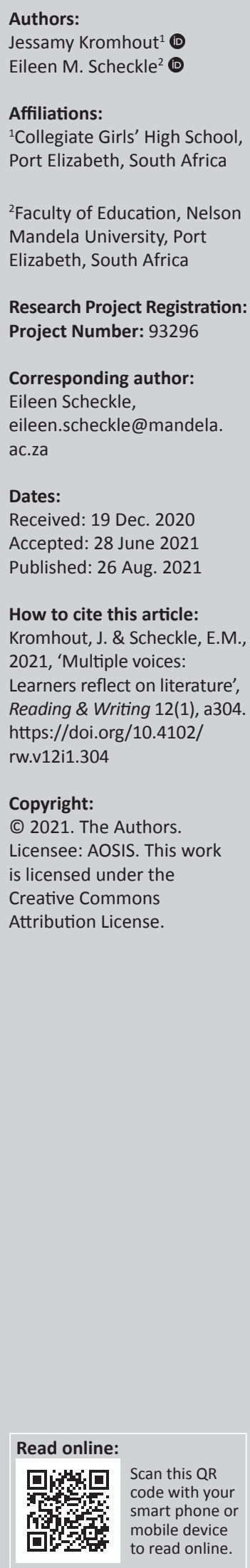

Background: Much of the research in literacy focuses on what learners fail to do, especially in the early grades, but it is equally important to research successful readers. In particular learners' experiences with literature contribute to our understanding of the possibilities literary texts offer. This article focused on learners' responses to Advanced Programme (AP) English, which was an optional subject offered at an ex-Model C school, to understand how the learners had taken up these literary texts.

Objectives: This study explored how matric learners spoke about the literature they had studied, in their AP English, in an informal group meeting.

Methods: A qualitative case study was used to explore learners' responses to literature. A final focus group meeting at the end of their matric year provides the data for this article. The transcriptions were coded using repeated patterns for themes to explore the stances taken in relation to the literature whether efferent or aesthetic.

Results: The data showed how learners had incorporated fragments from the literature into their own utterances so that their language use echoed the literature. In addition to an efferent exam focus, the literature and AP English practices were used in both Art and Home Language English examinations.

Conclusions: Learners need opportunities to talk about the multiple voices of literature in their lives. This kind of talk offers a different perspective on how literature can enrich, disrupt and extend learners' thinking about literature and themselves. This research offers a counterpoint to examination results and contributes to building a nation of readers.

Keywords: Advanced Programme English; literature; Bakhtin; dialogue; efferent and aesthetic responses; The Waste Land; multiple voices.

Elizabeth: I also quite like how, also just when you mentioned Ozymandias, how I've also like personally identified with one of the poems we've kind of learnt.

Emma: Anyone...

Elizabeth: But like like, you can, like of all the poems like you learn you can always go back to your favourite one. Because, okay, I'm going to use it, but for me Anyone [unclear] ... I used it in every single flipping exam because it was my favourite and I could really read deep into it, and I felt like I could just work with everything, just ... and when you find something like that that you really like and identify with, it's just so nice to know that you've got like ...

Patti: I can appreciate Anyone because, because I never really liked E. E. Cummings before that, and he's always been like one of those, "mm, I don't really, mm, I don't feel you". But then, but with Anyone like I enjoyed it more. Like, I feel, maybe he can write something.

Emma: And like, even when you take what people would call 'generic' poems nowadays, like The Tiger.

\section{Introduction}

The learners in this extract are reflecting on the poetry they encountered in the Advanced Programme (AP) English class. In particular, one used Ozymandias as an inspiration in her Art exam. Her classmate, Elizabeth, acknowledges her own connection to a particular poem which her friend suggests is Anyone. This is a reference to E.E. Cummings's poem Anyone lived in a pretty how town which Elizabeth reported using 'in every flipping exam'. A third learner, Patti, comments on Anyone and suggests it gave her a greater appreciation for the work of E. E. Cummings. The last comment refers to a 'generic' poem, William Blake's The Tiger. This conversation occurred in a focus group session at the end of the academic year where the participants reflected on the literature they had studied, specifically in their AP English class. 
This was an optional subject, from the Independent Examinations Board (IEB) curriculum, offered at an all-girls government school. So, in addition to the prescribed languages of Curriculum Assessment Policy Statement (CAPS), a Home Language and an Additional Language, these learners chose to also do AP English which focused on literary studies, including film, and expected a level of intertextuality where learners made links between the different texts studied (IEB Curriculum Statement 2008). The focus group occurred on a Saturday morning in the school library after they had completed their final English exams so this in no way contributed to any formal assessment. Instead, it was a space to reflect differently and share their various responses to literature as we were interested in how they would talk about their literary experiences.

Talking about literature is a means to make sense of it. In fact, learners themselves state they don't understand what they have read until they have spoken about it (Chambers 1996) and others appreciate literature more when they have had a chance to discuss it (Hébert 2008). Talk also provides insight into both individual learners' thinking as well as how cumulative dialogical exchange deepens participants' engagement with literature. For those concerned with improving literacy it is useful to see a vignette of school learners discussing their personal responses to literature and get a sense of the trajectory of school literacy (Cliff Hodges 2010a).

Much of our literacy research in South Africa focuses on what learners cannot do in relation to texts. The Progress in International Reading Literacy Study (PIRLS) tests revealed how our young learners struggle to find basic information in texts (Howie et al. 2011,2017). While the use of decontextualised passages to assess how well learners read has been critiqued (Janks 2011; Prinsloo \& Krause 2018), these tests, like PIRLS, are still an indication that our young learners struggle to make meaning from the texts. What is also worrying from the cycle of PIRLS tests is that in addition to the majority of learners not reaching the lowest benchmark, at the other end of the scale, the number of learners who achieve the highest benchmark on PIRLS has also declined (Howie et al. 2011). This means that even in the best resourced schools with a reading culture, fewer Grade 4 and Grade 5 learners reached the advanced benchmark where learners are expected to 'integrate ideas as well as evidence across a text to appreciate overall themes, understand the author's stance and interpret significant events' (Howie et al. 2017). As educators in South Africa, we need to maintain, sustain and grow any pockets of excellence as we would like to move a growing number of learners to these high benchmarks.

At one end of the education continuum is the recognition that success in early grade literacy is an important foundation for academic progress and enjoyment. So early grade literacy has been the focus of considerable research which often positions our young learners as deficient. At the other end of the education continuum, there is little qualitative research that explores matric learners' literacies and in particular their responses to literary texts. Matric learners talking about their responses to literature also provides an example of how literature can be meaningful for learners - something that testing does not explore. This article therefore examines research done with matric learners and focuses on how they talk about literature (Varga et al. 2020) to understand how they connected with the literary texts they had studied. In particular, this article focuses on learners' aesthetic stance towards literature (Rosenblatt 1991) as an indicator of both personal enjoyment and meeting the CAPS development goals for literature study.

The study of literature has always been a significant component of the English Home Language curriculum especially at the Further Education and Training (FET) level where 'Literature Study' is repeated throughout the CAPS teaching plan and warrants a two-and-a-half-hour examination. The CAPS document also suggests that at Home Language level of study, learners will develop their 'literary, aesthetic and imaginative' (CAPS 8) abilities and that through engagement with literature learners will develop a sensitivity to language 'that is more refined, literary, figurative, symbolic and deeply meaningful than much of what else they may read' (CAPS 12). The AP English curriculum extends this goal with an exclusive focus on a deep appreciation of literature in English and the development of intertextuality and connections across texts.

These learners' conversations about literature need to be contextualised and explored with reference to Rosenblatt's (1991) efferent and aesthetic approaches to literature. This will be supplemented with a discussion of talk and how Bakhtin's (1981) concepts of dialogic talk, in particular, provides a lens to examine learners' dialogic engagement and intertextual links. Bakhtin's interest in literature and his concept of double-voicedness echoed the multiple voices in The Waste Land which became a motif in this study.

\section{Literature Sketching the research landscape}

Not much research has been written on matric learners' responses to literature or even on the relevance or importance of literary texts for youth in the South African context. Instead, research studies have, justifiably, pointed to problems or gaps in our literacy education. For example, a survey of the articles in Reading $\mathcal{E}$ Writing, looking at the titles and key words between 2015 and 2020, suggests that most research is carried out at the tertiary level (see Boakye \& Linden 2018; Nkoala 2020) and includes academic literacy across faculties (see Andrianatos 2019; Drennan 2017; Esambe, Mosito \& Pather 2016) as well as teacher education courses (see Kimathi \& Bertram 2020; Moodley \& Aronstom 2016) or teacher practices (see Cekiso 2017; Madikiza, Cekiso, Tshotsho \& Landa 2018). Digital literacy has featured regularly and was the focus of a special collection in 2018. Challenges in developing literacy in the Foundation Phase feature regularly (see Cilliers \& Bloch 2018; Daries \& Probert 
2020; Nkomo 2018; Stoffelsma 2019) and less so at the Intermediate Phase (Beck \& Condy 2017). As expected, multilingual challenges cut across all educational levels and include practices of code-switching and translanguaging in English First Additional Language contexts (see Akinyeye \& Plüddemann 2016; Hungwe 2019). These research studies clearly reflect the over-riding concern with access to literacy, often powerful forms of literacy (see Gennrich \& Dison 2018; Lloyd 2016), and the various challenges in developing levels of literacy that will enable learners, at whatever level, to exploit their literacy prowess in their personal and educational pursuits (see Olifant, Cekiso \& Rautenbach 2020). Cliff Hodges (2010b) noted a similar pattern in the United Kingdom Literacy Association (UKLA) journal Literacy, with scant research on learners' responses to literature, especially in the higher grades.

In addition to surfacing the challenges and inequalities in the educational landscape, it is also valuable to see another side of literacy: what learners might do with texts beyond the requirements of passing exams, how learners talk about what they have read and how the literature they have read at school informs their personal and academic lives. Although CAPS purports to encourage an appreciation for literature, assessing learners via an examination seems to mitigate this. The National Reading Coalition (https://nrc.org.za/) has extended notions of reading practices. In particular, reading for pleasure and gaining insights into ourselves and the world around us has informed the President's Reading Circle initiative which seeks to cultivate:

a love of books and reading that will open our minds and hearts to new ideas and lock in opportunities that flow from a broadened understanding of the country and the world around us. (https://nrc.org.za/president-reading-circle/)

Ideally, learners would develop a love of reading literary texts through their engagement with these at school but this personal response needs to be affirmed and nurtured. The requirements of the examination system and the need to produce essays that meet these requirements mitigate against this (Doecke et al. 2009). Both teachers and learners are assessed on how successfully they navigate this system, which may leave little space for developing a personal response to the literature.

\section{Bakhtinian theory}

Bakhtinian theory offers several entry points to understanding learners' responses to literature. Firstly Bakhtin (1981) suggested that all literature contains echoes of previous utterances which are taken up and used afresh by different speakers. Thus, speakers recontextualise what they have read in new circumstances and nothing is completely new or original. As 'the word is born in a dialogue as a living rejoinder' (Bakhtin 1981:279), the social, interactive, generative elements of language are stressed as people draw on different levels of language in a heteroglossic mix. Secondly Bakhtin recognised different forces at play in language use, namely centripetal, a pull towards a central standardised language, and centrifugal, an outward, sometimes playful, and colloquial language use. These two forces he suggested act in tension. The centripetal forces of language serve to pull language towards the centre and result in common unitary languages that people share (Bakhtin 1981). This understanding of languages as singular and standard ignores the contributions and purposes of the language users (Bakhtin 1981). The individual's voice, used in a dialogic context, may be fragmented, may draw on different levels and generational uses of language, and thereby exert a centrifugal force. As languages are used and speakers draw on other utterances and frame them uniquely in the mixing of 'different linguistic consciousnesses' (Bakhtin 1981:429), languages become heteroglossic and hybrid. A singular, unitary language only exists as a concept; instead there are contextualised variations in talk so there are multiple meanings expressed by multiple voices (Newell 2019). Meaning making occurs in dialogic spaces where many voices are heard, rather than monologic, teacher-dominated spaces.

\section{Understanding literary responses}

Engagement with literature and the reader's personal response has been difficult to pin down (Hébert 2008), especially among young adults. Rosenblatt (1994) proposed a distinction between efferent and aesthetic reading and argued that the reader's personal response was central to an appreciation of the text. An aesthetic stance involves a personal appreciation as opposed to an efferent approach in which the reader is concerned with finding and possibly sharing information. Although both of these responses to literature may be activated interchangeably, school engagement with literature involves 'discourse production' (Hébert 2008) in the form of examinations or essays to be evaluated. So the efferent approach, in Rosenblatt's (1991) terms, is prioritised.

An aesthetic stance, which values the 'penumbra of private feelings, attitudes, sensations and ideas' (Rosenblatt 1994:184), is based on the interactions between the readers and the text in the activity of reading. In this process, what the reader brings to the text is central to the meaning that is created. Therefore, there would be no true or singular meaning that the reader is trying to uncover. Similarly, transformative reading (Fialho 2019) focuses on reading as a literary engagement with personal connections. She suggests that this kind of reading recognises the reciprocal exchange between reader and text and suggests that through this personal involvement in the text, one's sense of self is modified and expanded or augmented as there is a personal awakening (Fialho 2019).

Responses to literature extend beyond personal involvement and appreciation. Reading literature that excites the imagination prompts learners to 'reflect on themselves as human beings as they shuttle back and forth between literature and life' (Cliff Hodges 2010b:66). Thus, their knowledge of themselves and the world expands. As the readers enter the fictional world and journey together with 
the characters, they experience a vicarious world, understand choices made and develop empathy (Gabrielsen, BlikstadBalas \& Tenaberg 2019). When readers identify with a character's actions and understand the character's perspectives it can result in reducing prejudice and accepting diversity (Vezalli, Stathi, Giovannini, Capozza \& Trifiletti 2015). The value of literary reading lies in the accretions of experiences and 'the power of the text to linger' (Cliff Hodges 2010b:67) and motivate re-reading and further reading.

\section{Talking literature}

A sociocultural perspective involves understanding what people do with literacy (Heath 1983) and in this case with literary texts. In particular, a sociocultural understanding involves a closer look at the meaning and meaningfulness of these texts for these learners outside of the classroom. Talking about texts provides a space to think together with others and develop an understanding from the cumulative knowledge that is shared in a collaborative enterprise (Mercer \& Howe 2012). Busch (2010) argues that both the social context and the relationship between users contribute to the meaning making. If learners have not had wide exposure to books and stories as Heath (1983) recognised, then they need many opportunities to engage with books and 'require socialization into the ways of making sense of literary meaning and values' (Gabrielsen et al. 2019). This socialisation frequently occurs through talk, often at a socio-cognitive level in classrooms (Hébert 2008).

Talking about texts is central to experiencing literature and making sense of what is read (Hébert 2008). The power and possibilities for talk and learning from talk are evident in research in literature circles (Daniels 2002; King 2001) or book clubs (McMahon \& Raphael 1997; Tichenor, Piechura, Diedrichs \& Heins 2020) which are premised on the notion of dialogic talk to develop learning (Eeds \& Wells 1989). In these examples of literary talk, speakers take up and echo the words from the text both in their meaning making and in taking ownership as 'how students talk about literature matters' (Gabrielsen et al. 2019). Talking about literary texts 'helps to confirm, extend, or modify individual interpretation and creates a better understanding of the text' (Eeds \& Wells 1989:27). If a dialogic space is created in which responsiveness is encouraged, longer exchanges of exploratory talk result (Boyd, Tynan \& Potteiger 2018). When learners engage in reflective talk, where they reflect on their thinking and learning processes, they begin to make meaning of their values and beliefs and the discussions that result 'can lead to the transformation of ideas and actions' (Vetter \& Meacham 2018:229). Encouraging talk about the literary texts motivates thinking and reflection, especially when the educator figure wants to learn about the learners' responses to the texts (Boyd et al. 2018). Cliff Hodges (2010b) argues that it is important to pay attention to those learners who do read if we want to understand the complexity of reading and to value learner voices.

\section{Methodology Design}

This study was part of a larger case study (Yin 2009) investigating learners' experiences of an AP English course. This was a 2-year programme that focused on literature and intertextuality. The data for this article came from a focus group reflection at the end of the learners' matric year. As part of the case study this article offers a vignette (Creswell 2013), or a moment in time, of these learners' thinking about literature and possible connections they had made.

\section{Participants}

Eleven learners from a group of 12 participated in the final focus group meeting after completion of their final exams. The choice of meeting day and time was negotiated with the learners to fit in with their academic schedules. The participants chose to meet on a Saturday morning in the school library. All ethical procedures were complied with as permission had been sought from parents and school administration for the case study and assent or consent depending on participants' ages. Participants' anonymity was protected by the use of pseudonyms, in this case characters from literary fiction were chosen in line with the literary focus of the study.

\section{Data collection method and procedure}

The reflection session consisted of individual writing and a focus group meeting. Although this article will focus on what emerged during the focus group, the writing provided a space to focus on the AP English experience. Talk is often used as a precursor, or scaffold, for writing, so that learners try out their ideas orally (Chambers 1996) and build on each other's understanding (Beattie 2007) in preparation to write. However, writing can also be a form of thinking as Pelias (2011) suggests that in the process of writing, understanding becomes clearer. In an effort to prompt their writing and channel their thinking to their AP English, learners were also given an outline of a body and invited to reflect on the course using the metaphor of Written on the Body, which echoed Jeanette Winterson's (1992) eponymous novel with the palimpsest suggestion of layers of writing overlaid with later thinking. Thereafter the participants gathered and responded to the prompt on what was meaningful about their AP English experiences. This was a dialogic space 'predicated on ceding to students a degree of control of both content and behaviour' (Alexander 2018:31) where the learners took ownership of the discussion, which was supportive and respectful, thus meeting some of Alexander's criteria for dialogic learning. Besides the opening and closing remarks, the teacher was silent and instead the learners proffered their thoughts and reflections on their AP English experience and built on each other's comments. The focus group discussion was recorded and transcribed.

\section{Data analysis}

Using content analysis, the transcriptions of the focus group were coded for different themes to find repetitive 
patterns (Saldanha 2009). Firstly, we looked at how the learners spoke about the literary texts and how these informed different aspects of their lives. This also included particular positions and attitudes with regard to literature as they looked ahead to their future studies beyond secondary school. Unsurprisingly there was a focus on literature in their academic lives, in terms of both Home Language English and other subjects such as Art. In addition, there were specific comments on the literary engagement process of exploring poetry in particular and their growing appreciation for specific poems that resonated with individuals. In line with this qualitative approach and dialogic sharing, codes were emergent (Creswell 2013) as evidenced in the participants' utterances. The analysis also considered Rosenblatt's (1991) efferent and aesthetic stances in an effort to understand how learners used texts outside of the evaluative setting of literature examinations.

\section{Findings}

As indicated, the focus group meeting occurred at the end of the matric year. As such it was an opportune moment for reflection before the participants embarked on tertiary studies and adult life. Thus, this article presents a vignette of their thinking at this moment in time. We were interested in capturing and understanding how the literature of the AP English course might have informed the thinking and lives of the participants. It should be noted that for these learners the literature and the approach to literature were all part of the AP experience; however, in the analysis we will try to disentangle these. Our focus first is on the literature and particularly the poetry and thereafter on the AP English experience

\section{'The Waste Land'}

The opening extract between Elizabeth, Emma and Patti reflects the interactive and shared nature of the group who could anticipate each other's poetry preferences. Their conversation shifted from Shelley's Ozymandias, to E. E. Cummings's Anyone lived in a pretty how town, and how this poem became a resource in writing examinations. The conversation built on an understanding of Cummings' oeuvre and how this poem led to an increased appreciation of Cummings's work in general. The dialogue developed further with a reference to Blake's The Tiger, which is described as a 'generic' poem, or one that could appeal quite widely. In the following extract Patti reflects on how AP English lingered with her in her Art class:

Patti: I wish I'd used 'A hand full of dust' as a title for like this thing that I did with hourglasses and skulls turning into fish and stuff ... that was cool.

\section{Girls: $\quad$ (Laugh followed by pause)}

Patti: But then I suppose also my love affair with Ozymandias ...

\section{Girls: (Chuckle)}

Patti: $\quad$ And um, but I had an artwork that was almost also subconsciously more based on Ozymandias, well I suppose now when I look back and reflect, I'm like that's what I called this artwork, it's Ozymandias. It's like the skull, and then there's mountains, and there's this dude walking into the mountains but there's like no hope forwards or backwards, and there's just like ... emptiness.

Scout: $\quad$ Almost like ... ya (Chuckles)

Patti: Right? But it was like something I didn't actually realise it was affecting me that much until like, you know, afterwards it was like, 'Wow'.

In this interaction we see how Patti moves from fragments of The Waste Land to a recognition of how images from Ozymandias informed her artwork thinking. Her description of her artwork suggests a level of abstraction, and reflects how comfortable she feels with using multiple images or ideas. She refers to her love affair with the poem and, in this way, she positions herself in relation to the poem by emphasising how much she appreciates it.

Bakhtin's term 'generational language' (Bakhtin 1981) also ties in with the language she uses here, as she uses the word, 'dude', as well as 'like' which is littered throughout the discussion. The generational language serves to unify the participants as they are part of a particular generation of people, but it also serves to decentralise the meaning found in Ozymandias, as the centripetal and centrifugal forces are at play. This mixing of two different linguistic forms, sometimes from varied historical periods, in one concrete utterance is an example of Bakhtin's hybridity. As a result, this manner of mixing different languages has the possibility of creating a dynamic space that allows for new meaning, such as Patti's artwork or her ability to talk about poetry in a way that makes sense to her. This open discussion between the participants is the 'quintessential form of dialogic interaction' (Applebee et al. 2003:700) as the learners themselves lead and volunteer their own contributions as they reflect on how they used literature. In particular they seem to draw on their knowledge of literature and apply it across academic disciplines. When Elizabeth claims she used Anyone in 'every flipping exam', she does not specify particular subject areas, although it does seem as if it was widely applied. Similarly, Patti's artwork was infused with images from the literature they had studied in AP English and she recognises that this was done subconsciously and only on reflection did she observe the connections between her art images and literature.

Emma also draws on The Waste Land and recontextualises it in a different interaction:

Emma: I love the way ... I actually love the way we've learnt how to intertextualise everything [regardless of the fact that we do different poems?] that we do in English, but I mean books that we've read in the past that we may have forgotten about. It's like, 'Oh my word! That actually, you know, it links with that'. And I find it so weird, like Anais said, when she writes Paper 3 and T.S. Eliot comes in, what I found is that when I ... for arguments or discussions, or when I'm 
trying to persuade something, Waste Land comes in (giggles) ... it's like a random line from one of the poems. Then I'll actually stop, and like, 'Waaaiitt ...' that kind of thing. I did this to my mom, I don't know what we were doing. I was trying to persuade her of something and I just said, 'I will show you fear ...'.

Here she recognises how she has made connections across texts and has seen links to previous novels she has read so that the literary works speak to each other in her sense making. This stepping back and thinking about her thinking is a significant metacognitive indicator as she is showing an awareness of what is informing her responses to text: her previous literary encounters. In these exchanges we can see how the 'social, cognitive and metacognitive aspects ... of the discussion are intertwined' (Hébert 2008:30). In addition, she draws on literary language 'for arguments or discussions', and specifically uses The Waste Land. In trying to persuade her mother she makes recourse to 'I will show you fear ...' so the literary language of the classroom has been transposed and repurposed for persuasive family talk.

\section{'Revolutionary Road'}

Literature has the potential to challenge, cause discomfort or disrupt our thinking. Anna comments on another text, in this case the film Revolutionary Road, and recognises that literature can affect one on a deeper, uncomfortable level. She states:

'And for example, Revolutionary Road ... now at first I didn't really like it because it felt far too familiar to me. I could associate myself with April and I know what she felt like, which was scary. Because you're forced to see something, realise that you identify with it, and realise that you feel that way, and that is a part of you.' (Anna)

Anna is able to identify with the character of April and, as a result, she recognises that she has the potential to think and act in a similar fashion to the character. This resonates with Zadie Smith's suggestion that literature challenges our sense of self:

A great piece of fiction can demand that you acknowledge the reality of its wildest proposition, no matter how alien it may be to you. It can also force you to concede the radical otherness lurking within things that appear most familiar. (Smith 2007)

Anna goes on to say how the literature required her to reflect on a deeper, uncomfortable level. She states that:

'Like, there was a lot of ... of heavy stuff. Like Waste Land. But ya, other than that ... like that's why like on my thing that I wrote here, 'The hands felt the grit of ideas that didn't want to be dealt with or confronted'. Like me with Revolutionary Road. I felt trapped and I felt suffocated, whereas the thought of comfort was no longer there anymore. But then the other hand grasps hope. It's the hope of a sunflower, the hope of the little black boy, that there is hope in all that darkness, which is kind of a valid.'

It is important to recognise that literature also includes the 'heavy stuff', which has the power to linger and in so doing 'provokes thought about moral social and spiritual issues'
(Cliff Hodges 2010b:67). Despite the negative associations of the poem The Waste Land and the film Revolutionary Road, Anna does make reference to more positive aspects of the literature which include her references to the Romantic poetry that was studied, which includes the poems $A h$ ! Sunflower and The Little Black Boy by William Blake.

\section{Advanced Programme English experience}

Although the pedagogy of the AP English classes is not the focus of this article, many of the learners commented on how this course informed their thinking, as they made intertextual links across literature. In addition, there were observations about practice such as Emma's comment 'that in my vocabulary "Add English" has now become a verb' and that she applies the thinking to her other subjects, particularly Home Language (HL) English. She is aware of the different requirements of English HL and noted:

' $[W]$ ith the poetry that we're doing in class, I find all these connections and like, I want to write this, but no, it's Add English. This is normal English, just talk about the poem itself.' (Emma)

This comment suggests the more limited focus of the HL examination. The learners have developed such a familiarity with the poems that Anna says 'we have to look at the poetry as people'. She adds 'like you've met The Tiger. You can kind of figure out what kind of person they'd be, where they'd come from'. Other learners spoke about their awareness of literature in general. For example, Scout mentioned that 'Add English was, was a stepping stone, a launching pad'. She felt that 'we're like on the threshold of the front door, not even through the front door' and 'I'm absolutely starving. I want more literature and Add English has given me that'. Many of these responses carry suggestions of Fialho's (2019) personal awakening as the texts linger powerfully in their lives (Cliff Hodges 2010b). Anais picked up this idea of the world of literature and shared 'I started reading Emma by Jane Austen the other day and, okay, I don't like the main character and I'm still ... I'm trying to read'.

Others looked back at their days of reading Twilight and contrasted it with their current reading and future goals to read Anna Karenina, Jane Austen and The Book Thief(Elizabeth), Ulysses (Scout) or Charles Dickens, the Brontës and Alexander Dumas (Emma). From this discussion it would seem that these are committed readers, aware of their trajectories of reading (Cliff Hodges 2010a) that extended from early grades through their AP English into future reading goals.

\section{Discussion}

In these extracts we see how in the reading process, the readers bring their previous knowledge of the world and of texts to each new text they encounter (Boyd et al. 2018). This knowledge of the world and other texts that have been read informs and enhances the meaning-making process (Rosenblatt 1991). Dialogic interactions allow for rich meaning-making opportunities as the participants bring varied experiences and backgrounds (Newell 2019) to this joint interpretation 
exchange construction. The reader who has encountered many texts brings these multiple voices and recognises echoes and allusions in each new textual reading, in the form of a Bakhtinian dialogic exchange. This kind of reading is more than comprehension as it is rather an interplay between the previous and new (Hébert 2008) in accretions of appreciation and literary playfulness. Learners make meaning of the text as the multiple voices of the class, the teachers and the texts themselves (Newell 2019) are brought into dialogue. It seems axiomatic to suggest that the more learners have read, the more they can appreciate and draw from new texts; indeed these learners have shown how they have multiple voices to mobilise in their meaning making of future texts.

Learners who chose to be part of the AP English were expected to demonstrate their in-depth knowledge of individual texts as well as to make connections across texts and thus display intertextuality in their writing. This demonstration of understanding required an efferent approach (Rosenblatt 1991), as examinations demand a public display of knowledge (Hébert 2008). The timing of the focus group, immediately after examinations, also meant examinations were uppermost in the learners' minds. In addition to the connections to examinations and schoolwork, learners' focus group comments also included some very personal responses at the aesthetic end of the continuum. An example of this is in the opening extract where the learners commented on a personal poem, or one that resonated with an individual. Anna's strong emotional responses to Revolutionary Road is also at the aesthetic end of the continuum (Rosenblatt 1991). What Rosenblatt (1991) recognises is that these reading stances are not in opposition, but are often taken up interchangeably. She argues that the purpose of the text should determine the stance of the reader, so that scientific texts would require an efferent stance whereas literature, involving literary appreciation, would require an aesthetic appreciation of the images and language of this text (Rosenblatt 1991). While the learners here shuttled between efferent and aesthetic stances, they also stepped back and considered their positions with regard to literature so that for some literature was presented as a metaphorical person with whom they had a familiar relationship and for others literature could be both inspirational and aspirational, as seen in their reading goals. Literature that is inspirational is carried beyond the text and continues to reward the reader, as rereading novels can reveal new 'nuggets', according to Emma. If we want a nation of readers, we need learners who have reading goals and a strong inclination to read widely and read for pleasure. This is surely one of the major goals of our education system that needs further exploration.

\section{Limitations}

This article offers a small glimpse into what learners may say and do with the literature they have read. We acknowledge that as a small-scale study at a former model C school, it might be far removed from the literacy challenges facing the majority of educators and learners in South Africa. We also do not want to suggest that these learners are in any way model learners but instead recognise that they have had educational and social advantages that have included access to a wide array of literature. Instead, our focus is to share possibilities of engagement with literature and to recognise how learners take up the texts they have encountered and recontextualise and repurpose them for various contexts.

\section{Conclusion and recommendations}

In conclusion, this study has sought to understand how a group of AP English learners reflected on the role of literature in their lives, both in and out of school. Although this vignette presents a window in time, their multiple voices suggest a trajectory of reading that has led to this appreciation of literature and a sense of future readings. If we are to build a reading culture, we need to open up spaces for learners to talk about their reading and exchange ideas. In addition to providing suitable and varied books, we need more informal spaces where the voices of the learners can explore the voices of the literature in an aesthetic rather than an efferent approach. If research is to be of any value, it needs to feed back into the quality of teaching and learning in the classroom (Cliff Hodges 2012) and allowing multiple viewpoints is an encouraging shift towards developing a personal response to literature. In this way, we need no longer live in a 'waste land', but we are able to occupy a rich and generative space that gives people the freedom to encounter literature through multiple perspectives.

\section{Acknowledgements Competing interests}

The authors have declared that no competing interest exists.

\section{Authors' contributions}

J.K. did the original research, generated and analysed the data together with her supervisor, E.M.S. E.M.S. reanalysed the data and wrote this article.

\section{Ethical considerations}

All ethical procedures were observed: permission was sought and approved from the Nelson Mandela central ethics committee. Permission was sought and approved from the school principal, parents and learners as well as from the Department of Basic Education (H15-EDU-ERE-014).

\section{Funding information}

This work was undertaken as part of a South African National Research Foundation (NRF) funded project entitled 'Dialogic engagement between local and university communities: Enabling agency towards active citizenship in the context of education'. Grant number 93296.

\section{Data availability}

Transcriptions of the focus group discussion are available from the authors. 


\section{Disclaimer}

The views and opinions expressed in this article are those of the authors and do not necessarily reflect the official policy or position of any affiliated agency of the authors.

\section{References}

Akinyeye, C \& Plüddemann, P., 2016, 'The story of a narrative: Teaching and assessing English in a township school', Reading \& Writing 7(1), 1-8.

Alexander, R., 2018, 'Developing dialogic teaching: Genesis, process, trial', Research Papers in Education 33(5), 561-598. https://doi.org/10.1080/02671522.2018.148 1140

Andrianatos, K., 2019, 'Barriers to reading in higher education: Rethinking reading support', Reading \& Writing 10(1), 1-9

Applebee, A., Langer, J., Nystrand, M. \& Gamoran, A., 2003, 'Discussion based approaches to developing understanding: Classroom instruction and student performance in Middle and High School English', American Education Research Journal 40(3), 685-730. https://doi.org/10.3102/00028312040003685

Bakhtin, M., 1981, The dialogic imagination, four essays, University of Texas Press, Austin, TX.

Beattie, A., 2007, 'Exploring the value of dialogue in improving boys' writing', Changing English 14(2), 161-174. hhtps://doi.org/10.1080/13586840701442976

Beck, S. \& Condy, J., 2017, 'Instructional principles used to teach critical comprehension skills to a Grade 4 earner', Reading \& Writing 8(1), 1-8.

Boakye, N.A.Y. \& Linden, M. 2018, 'Extended strategy-use instruction to improve students' reading proficiency in a content subject', Reading \& Writing 9(1), 1-9.

Boyd, M., Tynan, E., \& Potteiger, L., 2018, 'Trusting the local: Opening up the script with response-able talk practices', English Teaching: Practice \& Critique 17(1) 2-15. https://doi.org/10.1108/ETPC-09-2017-0125

Cekiso, M., 2017, 'Teachers' perceptions of reading instruction in selected primary schools in the Eastern Cape', Reading \& Writing 8(1), 1-8.

Chambers, A., 1996, Tell me: Children, reading and talk, Stenhouse, York.

Cilliers, L. \& Bloch, C., 2018, 'A reading project to improve literacy in the foundation phase: A case study in the Eastern Cape', Reading \& Writing 9(1), 1-7.

Cliff Hodges, G., 2010a, 'Rivers of reading: Using critical incident collages to learn about adolescent readers and their readership', English in Education 44(3), 181-200. https://doi.org/10.1111/j.1754-8845.2010.01072.x

Cliff Hodges, G., 2010b, 'Reasons for reading: Why literature matters', Literacy 44(2), 60-68. https://doi.org/10.1111/j.1741-4369.2010.00552.x

Cliff Hodges, G., 2012, 'Research and the teaching of English: Spaces where reading histories meet', English Teaching Practice and Critique 11(1), 7-25.

Creswell, J., 2013, Qualitative inquiry and research design, Sage, Thousand Oaks, CA.

Daniels, H., 2002, Literature circles: Voice and choice in book clubs and reading groups, 2nd edn., Stenhouse, Portland, ME.

Daries, M. A. \& Probert, T., 2020, 'A linguistic analysis of spelling errors in Grade 3 isiXhosa home-language learners', Reading \& Writing 11(1), 1-10.

Doecke, B., Gill, P., Illesca, B. \& Van de Ven, P.-H., 2009, 'The literature classroom: Spaces for dialogue', L1 - Educational Studies in Language and Literature 9(1) 5-33. https://doi.org/10.17239/L1ESLL-2009.09.01.03

Drennan, L. M., 2017, 'Traversing the spaces of higher education through writing', Reading \& Writing 8(1), 1-18.

Eeds, M. \& Wells, D., 1989, 'Grand conversations: An exploration of meaning construction in literature study groups', Research in the Teaching of English 23(1), 4-29.

Esambe, E., Mosito, C. \& Pather, S., 2016, 'First-year students' essay writing practices: Formative feedback and interim literacies, Reading \& Writing 7(1), 1-11.

Fialho, O., 2019, 'What is literature for? The role of transformative reading', Cogen Arts \& Humanities 6(1), 1-16. https://doi.org/10.1080/23311983.2019.1692532

Gabrielsen, I.L., Blikstad-Balas, M. \& Tengberg, M., 2019, 'The role of literature in the class-room. How and for what purposes do teachers in lower secondary schoo use literary texts?', L1-Educational Studies in Language and Literature 19, 1-32. https://doi.org/10.17239/L1ESLL-2019.19.01.13.

Gennrich, T. \& Dison, L., 2018,' Voice matters: Students' struggle to find voice', Reading \& Writing 9(1), 1-9.

Heath S., 1983, Ways with words: Language, life and work in communities and classrooms, Cambridge University Press, New York, NY.

Hébert, M., 2008, 'Co-elaboration of meaning in peer-led literature circles in secondary School: The interplay between reading modes, quality of talk, and collaboration modes', L1 -Educational Studies in Language and Literature 8(3), 23-55. https://doi.org/10.17239/L1ESLL-2008.08.03.02
Howie, S.J., Combrinck, C., Roux, K., Tshele, M., Mokoena, G.M. \& McLeod Palane, N., 2017, PIRLS LITERACY 2016: South African Highlights Report, Centre for Evaluation and Assessment, Pretoria.

Howie, S.J., Van Staden, S., Tshele, M., Dowse, C. \& Zimmerman, L., 2011, Progress in International Reading Literacy Study 2011. Summary report. South African children's reading literacy achievement, Centre for Evaluation and Assessment, University of Pretoria, Pretoria.
Uniliten's reading literacy acy St

Hungwe, V., 2019, 'Using a translanguaging approach in teaching paraphrasing to enhance reading comprehension in first-year students', Reading \& Writing 10(1), 1-9.

IEB, 2008, Curriculum statement grades 10-12 (General), viewed n.d., from www.ieb. co.za/School/nsccurriculum/advanced\%20programme\%20english.pdf.

Janks, H., 2011, 'Making sense of the PIRLS 2006 results for South Africa', Reading \& Writing 2(1), 27-39. https://doi.org/10.4102/rw.v2i1.11

Kimathi, F.K. \& Bertram, C. 2020, 'Oral language teaching in English as First Additional Language at the Foundation Phase: A case study of changing practice', Reading \& Writing 11(1), 1-10.

King, C., 2001, “I like group reading because we can share ideas": The role of talk within the literature circle', Reading 35(1), 32-36. https://doi.org/10.1111/1467 9345.00157

Lloyd, G., 2016, 'Are we teaching critical literacy? Reading practices in a township classroom, Reading \& Writing 7(1), 1-6.

Madikiza, N., Cekiso, M.P., Tshotsho, B.P. \& Landa, N. 2018, 'Analysing English First Additional Language teachers' understanding and implementation of reading strategies', Reading \& Writing 9(1), a170. https://doi.org/10.4102/rw.v9i1.170

McMahon, S.I. \& Raphael, T.E., 1997, The Book Club Connection: Literacy learning and classroom talk, Teachers' College Press and the International Reading Association, Newark, Delaware.

Mercer, N. \& Howe, C., 2012, 'Explaining the dialogic processes of teaching and learning: The value and potential of sociocultural theory', Learning Culture and Social Interaction 1(1), 12-21. https://doi.org/10.1016/j.Icsi.2012.03.001

Moodley, T. \& Aronstam, S., 2016, 'Authentic learning for teaching reading: Foundation phase pre-service student teachers' learning experiences of creating and using digital stories in real classrooms', Reading \& Writing 7(1), 1-10.

Newell, S., 2019, 'Learning in dialogue: An exploration of talk in an English Classroom', Changing English 26(4), 357-366. https://doi.org/10.1080/1358684X.2019.1645588

Nkoala, S. B., 2020, 'Student perceptions of multilingualism and the culture of communication in journalism studies in higher education', Reading \& Writing 11(1), 1-9.

Nkomo, S.A., 2018, 'Grade 3 learners' imagined identities as readers revealed through their drawings', Reading \& Writing 9(1), 1-9.

Oliphant, T. Cekiso, M \& Rautenbach, E., 2020, 'Critical reading perceptions and practices of English First Additional Language learners in Gauteng, Tshwane South district', Reading \& Writing $11(1), 1-11$

Pelias, R.J., 2011, 'Writing into position', in N. Denzin \& Y. Lincoln (eds.), The Sage handbook of qualitative research, pp. 662-663, Sage, Thousand Oaks, CA.

Prinsloo, M. \& Krause, S., 2018, 'Testing practice in a Southern school', in D. Bloome, J. Rowsell, C. Leung \& M.L. Castanheira (eds.), Re-theorizing literacy practices, pp. 154-167, Routledge, New York, NY.

Rosenblatt, L., 1991, 'Literature - S.O.S', Language Arts 68(6), 444-448.

Rosenblatt, L., 1994, The reader, the text, the Poem: The transactional theory of the literary work, Southern Illinois University Press, Carbondale, IL.

Saldanha, J., 2009, The coding manual for qualitative researchers, Sage, Thousand Oaks, CA.

Smith, Z., 2007, January 13, Fail better, viewed from http://faculty.sunydutchess.edu/ oneill/failbetter.html.

Stoffelsma, L., 2019, 'English vocabulary exposure in South African township schools: Pitfalls and possibilities', Reading \& Writing 10(1), 1-10.

Tichenor, M., Piechura, K., Diedrichs, R. \& Heins, E., 2020, 'Building a culture of independent reading through literacy clubs', Reading Improvement 57(1), 11-15.

Varga, Z., McGuinn, N., Naylor, A., Rimmereide, E. \& Syed, G., 2020, 'We are invited to imagine. Using a literary text to encourage cross-cultural dialogue about citizenship', Cambridge Journal of Education 50(4), 501-519. https://doi.org/10.1 080/0305764X.2020.1736002

Vetter, A. \& Meacham, M., 2018, 'The significance of reflective conversations for adolescent writers', English Teaching Practice and Critique 17(3), 228-244. https://doi.org/10.1108/ETPC-11-2017-0168

Vezalli, L., Stathi, S., Giovannini, D., Capozza, D. \& Trifiletti, E., 2015, 'The greatest magic of Harry Potter: Reducing Prejudice', Journal of Applied Social Psychology 45, 105-121. https://doi.org/10.1111/jasp.12279

Yin, R.K., 2009, Case study research: Design and methods, 4th edn., Sage, Thousand Oaks, CA. 